\title{
DE LA INDIGNACIÓN DE MARIANA FRANCO EN DESTILANDO AMOR A LA DEFENSA DE ANGÉLICA RIVERA EN YOUTUBE: LA ARGUMENTACIÓN DE LA «PRIMERA DAMA» MEXICANA ${ }^{1}$
}

\author{
Luis Bernardo Quesada NiETO \\ The Graduate Center, City University of New York (EE.UU.)
}

\section{RESUMEN}

El presente trabajo propone la lectura de algunos argumentos identificados en un video publicado por la actriz Angélica Rivera, casada entre 2010 y 2019 con el expresidente mexicano Enrique Peña Nieto (2012-2018), en su cuenta personal de YouTube en 2014. Este video constituye un evento importante en la defensa pública de la pareja presidencial, ante las acusaciones de corrupción por tráfico de influencias en la construcción y adquisición de una casa multimillonaria en la Ciudad de México. A partir de un análisis de la estructura y jerarquía argumentativas se plantea que el estilo discursivo de Rivera muestra paralelismos con un episodio de la telenovela Destilando amor, que protagonizó en 2007, y se establece una conexión entre ambos a partir del sistema de valores que estos materiales muestran. Las reflexiones finales problematizan la efectividad de la telenovela como recurso persuasivo de la industria cultural en la sociedad mexicana contemporánea, luego del malestar que el video de YouTube propició en medios y redes sociales, y sobre la incapacidad de las élites de gobierno para reconocer y empatizar con el pueblo gobernado, agraviado por la representación distorsionada que Rivera construyó de él.

PALABRAS CLAVE: análisis del discurso, argumentación, glotopolítica, industria cultural, telenovela, Angélica Rivera, Enrique Peña Nieto, PRI.

\section{ABSTRACT}

The present work proposes a reading of some arguments identified in a video published by Angélica Rivera, married from 2010 to 2019 to Enrique Peña Nieto,

\footnotetext{
${ }^{1}$ Agradezco el apoyo y sugerencias del profesor Oswaldo Zavala (CUNY) para la realización de este manuscrito, así como las lecturas y comentarios de Rosa Sánchez y Agnẻ Karosaitė durante el proceso de elaboración. Gracias a Itzia Alejandra Guillén Rivas, por su apoyo en labores de transcripción. Este texto se benefició ampliamente de los comentarios de los lectores anónimos de Oralia; a todos ellos doy las gracias muy especialmente. Los fallos son, por supuesto, todos responsabilidad propia.
} 
former president of Mexico (2012-2018), in her personal YouTube account in 2014. This video is an important event in the public defense carried out by the presidential couple, accused of influence peddling to build and buy a millionaire house in Mexico City. Drawing on the analysis of the argumentative structure and hierarchy of the video, I argue that Rivera's discursive style shows similarities with an episode of the soap opera Destilando amor, which she starred in 2007; the link between these materials can be plausibly grounded on the system of values which both of them show and share. Finally, I discuss the effectiveness of the soap opera as a persuasive device of the cultural industry in contemporary Mexican society, after considering the social rejection this YouTube video generated in social media, and discuss the government elite's disability to empathize and recognize the society it governs, a society that was aggrieved by the distorted representation that Rivera created.

KEYWORDS: discurse analysis, argumentation, glottopolitics, cultural industry, soap opera, Angélica Rivera, Enrique Peña Nieto, PRI.

Fecha de recepción: 16/04/2018

Fecha de aceptación: 27/07/2018

Fecha de la versión definitiva: 28/10/2018

\section{Contextualización}

El 9 de noviembre de 2016, contra todos los pronósticos publicados por diarios nacionales e internacionales y contra las predicciones de encuestas de días previos a la elección, el candidato Donald Trump obtuvo la mayoría de votos y se convirtió así en el presidente número 45 de Estados Unidos. Esta elección democrática de un personaje popularizado en buena medida por la industria del entretenimiento televisivo para un cargo público de tal envergadura, no obstante, encuentra un precedente inmediato en la política mexicana, con la cuestionada campaña electoral (2011), elección (2012) y mandato del expresidente Enrique Peña Nieto, entre 2012 y 2018. Ambos personajes pueden verse como casos demostrativos de un fenómeno de espectro global en el que la política y el espectáculo exhiben las complejas relaciones que mantienen entre sí. Los dos políticos fueron en buena medida el resultado de una imagen creada y reforzada por productos de la televisión tradicional: en Trump, el reality show (The Apprentice, 20042015); en Peña Nieto, la telenovela, donde la mediatización de su vida personal, como la transmisión en vivo de su boda con la actriz mexicana Angélica Rivera en 2010, se dio al mismo tiempo que su campaña política, presuntamente apoyada por Televisa, el principal conglomerado de medios mexicano.

Es importante subrayar que la elección de Peña Nieto, la de Trump y el evento discursivo particular que se estudia en este trabajo, son eventos 
que acontecen en un contexto en el que el consumo mediático, con las particularidades propias de las sociedades mexicana y estadunidense, se ha transformado y diversificado. Estos cambios parecen estar relacionados con la «democratización de internet», impulsados en buena medida por el abaratamiento de las tecnologías digitales. Desde finales de la primera década del siglo Xxi, este proceso ha provocado transformaciones no solo en la forma en la que se consume contenido, sino también en la forma en que se produce y distribuye. Quizás más importante, ha modificado la manera en la que la audiencia interactúa con este, y, en la medida en la que su consumo se ha diversificado, su oferta también lo ha hecho.

Como lo ha expresado el periodista y escritor Juan Villoro ${ }^{2}$, Peña Nieto es «el primer telepresidente de México». Su casamiento con la actriz Rivera, como la constante presencia de esta en los actos de la campaña electoral, y, posteriormente, su desempeño como «Primera Dama», son elementos clave para entender su llegada al poder y su mantenimiento en él, a pesar de polémicas y cuestionamientos públicos sobre su presunta participación en casos de corrupción como el que aquí se aborda, y por su respuesta ante casos de violación de derechos humanos durante su mandato, así como la desaparición de 43 estudiantes en el año 2014, en Ayotzinapa, Guerrero. El material que a continuación se analiza forma parte, también, de un contexto sociopolítico en el que, a grandes rasgos y desde hace décadas, han convivido en México la pobreza generalizada y los niveles de desigualdad social, con la violencia extendida por regiones, generada en buena medida por la política de seguridad contra el narcotráfico iniciada en el año 2006 por el expresidente Felipe Calderón (2006-2012), continuada por Peña Nieto hasta el fin de su sexenio en el 2018, elementos contextuales que en conjunto han generado un malestar generalizado en la población, llevando a Peña Nieto a romper el récord de menor popularidad de cualquier mandatario previo, con un índice de aprobación social del $17 \%$. Estos y otros sucesos contribuyeron a la derrota del partido del presidente, el histórico Partido Revolucionario Institucional (PRI), en las elecciones federales de 2018, en las que perdió buena parte de su peso político nacional, comenzando por la Presidencia de la República, que por primera vez en la historia moderna del país fue ganada por un partido autoproclamado de izquierda, el Movimiento Regeneración Nacional (Morena), fundado por el actual presidente Andrés Manuel López Obrador. En el 2018, el PRI perdió también la mayoría en la Cámara de Diputados y el

\footnotetext{
${ }^{2}<$ http://www.lanacion.com.ar/1745737-enrique-pena-nieto-un-presidente-hecho-enla-pantalla-que-hoy-prueba-el-mundo-real $>$.

${ }^{3}<$ https://www.eleconomista.com.mx/politica/Impacta-el-periodo-electoral-en-laaprobacion-del-presidente-20180301-0153.html>.
} 
Senado $^{4}$, además de la mayoría de las gubernaturas estatales y presidencias municipales que controlaba.

Con este marco de fondo, se propone el análisis del material que sigue: la defensa de Angélica Rivera en un video de YouTube ante los señalamientos de corrupción y tráfico de influencias que la involucraron a ella y al gobierno federal en una transacción inmobiliaria millonaria. El recorrido comienza con un recuento de los hechos que suscitaron la aparición del video. Se presenta una descripción metodológica, una base teórica, la transcripción del discurso de Rivera en YouTube y, finalmente, algunas reflexiones realizadas a partir de la argumentación de la actriz en dicho medio y a partir de su similitud discursiva/argumentativa con uno de los capítulos de la telenovela Destilando amor (2007), en la que llevó el papel protagónico, hasta la fecha el más exitoso de su carrera como actriz.

\subsection{El reportaje de Aristegui Noticias}

El 9 de noviembre de 2014, el medio electrónico Aristegui Noticias publicó un reportaje en el que daba a conocer la existencia de una casa relacionada con la familia presidencial ubicada en uno de los barrios más costosos de la Ciudad de México (Cabrera et al. 2014) ${ }^{5}$; dicha residencia habría sido construida por una empresa filial del corporativo Grupo Higa, Constructora Teya, consorcio que había obtenido la adjudicación de varios contratos por servicios y obras públicas contratadas por el Gobierno del Estado de México (Edomex), durante el mandato de Enrique Peña Nieto como gobernador de ese estado en el periodo 2005-2011.

Tras referir una entrevista de la revista ¡Hola! a la actriz Angélica Rivera, ya casada con Peña Nieto, y ya éste en el poder, realizada en «su propia casa», según consignó dicha revista en esta publicación de mayo de 2013, el reportaje de Aristegui Noticias concluyó, a partir de un exhaustivo trabajo de documentación periodística compuesto por planos arquitectónicos, entrevistas, testimonios, facturas, contratos y otros documentos, que la locación de la entrevista realizada por ¡Hola! a la llamada «Primera Dama» correspondía a la residencia edificada por Constructora Teya. Así, el reportaje de Aristegui Noticias, no solo establecía una relación entre este inmueble propiedad de la pareja presidencial y la empresa ganadora de concursos para realizar obras públicas en el Edomex, sino que además ponía en duda la veracidad de la declaración patrimonial del propio presidente Peña Nieto, quien antes de asumir el cargo y en atención al mandato constitu-

\footnotetext{
${ }^{4}<$ https://elpais.com/internacional/2018/10/08/mexico/1539021824_767096.html>.

5 <https://aristeguinoticias.com/0911/mexico/la-casa-blanca-de-enrique-pena-nieto/>.
} 
cional $^{6}$ había declarado que poseía cuatro casas y cuatro terrenos en el Estado de México y un departamento en el puerto de Acapulco, pero no esta, la llamada "casa blanca», como se la conoció en algunos medios de comunicación y redes sociales (Facebook y Twitter), como mofa a su estilo arquitectónico minimalista, de amplios y luminosos espacios, y como crítica a la opulencia y megalomanía de la pareja presidencial mexicana, asociando su proyecto con la residencia oficial del poder ejecutivo en Estados Unidos (The White House), como símbolo del mayor poder político en el mundo.

El cuestionamiento sobre el hecho de que una misma empresa fuera adjudicada con varios contratos millonarios para efectuar obras públicas en el Estado de México durante el periodo de Peña como gobernador, aunado a contratos adicionales a otra empresa filial del Grupo Higa, generaron un acontecimiento discursivo en medios de comunicación, que giró en torno a la presunta corrupción por tráfico de influencias en beneficio de los propietarios del corporativo, Juan Armando Hinojosa Cantú y su hijo Juan Armando Hinojosa García, como del propio Enrique Peña Nieto y Angélica Rivera.

El caso tuvo repercusión inmediata en medios electrónicos y redes sociales, que se constituyeron como espacios de protesta e indignación por la presunta práctica de corrupción. En la sección de comentarios del reportaje de Aristegui Noticias publicados hasta enero de 2017 aparecían 13437, la mayoría expresiones del malestar hacia la clase política y el gobierno mexicano, como hacia los excesos de la casa y sus propietarios, exhibidos por la revista ;Hola!, los cuales contrastaban con los altos niveles de pobreza en el país. La atención mediática que atrajo el suceso ocasionó que Rivera realizara un pronunciamiento público para explicar los hechos, una semana después de la publicación del reportaje en Aristegui Noticias, el 18 de noviembre de 2014, a través de un medio de comunicación no oficial y no convencional: su cuenta personal en YouTube.

El presente trabajo se centra en el discurso que constituye esa respuesta publicada por Rivera, vista como expresión de los procesos de comunicación pública al interior del sistema político mexicano, y como parte de una cultura de la transparencia y la rendición de cuentas, promovidas por un discurso democrático popularizado en las últimas décadas en el país.

\footnotetext{
${ }^{6}<$ http://www.diputados.gob.mx/LeyesBiblio/pdf/1_270818.pdf>, Artículo 108, Título Cuarto: «De las Responsabilidades de los Servidores Públicos, Particulares Vinculados con Faltas Administrativas Graves o Hechos de Corrupción, y Patrimonial del Estado».

${ }^{7}$ Estos comentarios de lectores han sido retirados de la página web de Aristegui Noticias: $<$ https://aristeguinoticias.com/0911/mexico/la-casa-blanca-de-enrique-pena-nieto/>. Contacté al medio vía correo electrónico a principios de octubre de 2018 para indagar sobre el particular, sin haber recibido respuesta.
} 


\section{Metodología/Enfoque}

Este trabajo pretende mostrar cómo la política de comunicación pública del gobierno federal mexicano (2012-2018) pareció hacer uso, sabiéndolo o no, de elementos discursivos propios del entretenimiento y la industria del espectáculo, con fines políticos específicos. Estos fines se corresponden con la intención de Rivera de probar su inocencia, y, de paso, librar a su esposo de culpa también. Como se verá, estas intenciones se encuentran mediadas por usos concretos de la lengua. Se adopta una perspectiva glotopolítica de análisis (Del Valle 2017), la cual parte de considerar todo uso lingüístico como atravesado por lo político (Joseph 2006), y de tomar en cuenta los contextos históricos en los que dicho uso lingüístico aparece para otorgarle un marco explicativo. Esta mirada glotopolítica sobre los fenómenos, se refuerza con el método de análisis crítico del discurso de Jäger (citado en Wodak y Meyer 2001), quien propone justificar la relevancia política y social de analizar un conjunto de datos empíricos, documentarlos y analizarlos lingüísticamente en función de su contexto social.

Con estas premisas como punto de partida, el camino que se sigue para conseguir el objetivo pasa por presentar las herramientas teóricas, primero las relacionadas con dos autores centrales de la Escuela de Fráncfort, Horkeimer y Adorno, congruentes con el enfoque glotopolítico, así como los planteamientos sobre la teoría de la argumentación de Perelman y Olbrechts-Tyteca (1969), en especial su propuesta sobre la estructura de los argumentos y los tipos de acuerdo sobre los que parte un discurso que busca persuadir a un auditorio. Enseguida se presenta el material, el discurso de Rivera, que consiste en una transcripción ortográfica en procesador de textos, segmentada en 30 enunciados para el análisis. A continuación, se organiza el contenido ideológico del discurso a partir de las contribuciones de Horkeimer y Adorno, por un lado, y las de Perelman y OlbrechtsTyteca, por el otro. Tras la lectura teórica de los datos se presentan algunas reflexiones.

\section{HERRAMIENTAS TEÓRICAS}

\subsection{Industria cultural}

Para Horkheimer y Adorno (1944 [2002]), la producción de arte masivo contribuye a crear una sociedad desinteresada que, eventualmente, y bajo circunstancias particulares, puede llevar a atrocidades como los campos de concentración y el genocidio nazis. Este arte masivo está relacionado con la «industria cultural» o industria del entretenimiento, «que 
produce películas, televisión, radio, revistas y música popular» y en la que resulta difícil distinguir los límites entre arte, publicidad y propaganda. Para Horkheimer y Adorno, el mundo del cine, como los demás productos de la industria cultural, ha sido absorbido por la sociedad, de modo que se le ha «enseñado» a esta qué contenidos esperar, recibiéndolos de manera automática o acrítica:

Anyone who is so absorbed by the world of the film, by gesture, image, and word, that he or she is unable to supply that which would have made it a world in the first place, does not need to be entirely transfixed by the special operations of the machinery at the moment of the performance. The required qualities of attention have become so familiar from other films and other culture products already known to him or her that they appear automatically. The power of industrial society is imprinted on people once and for all. (Horkheimer y Adorno 1944 [2002]: 99)

A partir de la producción y reproducción de esta industria del entretenimiento, se mantiene un status quo, en el que la sociedad termina por ser partícipe. Este status quo, que en palabras de los autores corresponde a «the old schema», es el estado que busca ser mantenido por el grupo o grupos en el poder:

The culture industry determines its own language positively, by means of prohibitions applied to its syntax and vocabulary. The permanent compulsion to produce new effects which yet remain bound to the old schema, becoming additional rules, merely increases the power of the tradition which the individual effect seeks to escape. (ibid. 101)

La industria cultural se manifiesta en distintas formas de entretenimiento y distracción. Horkheimer y Adorno emplean la metáfora del cine, que podría ser trasladada a la televisión y la telenovela, en tanto puede producir la misma sensación de comodidad y refugio que los autores refieren:

In stepping from the street to the cinema, [consumers] no longer enter the world of dream in any case [...] For the housewife, despite the films which are supposed to integrate her still further, the dark of the cinema grants a refuge in which she can spend a few unsupervised hours, just as once, when there were still dwellings and evening repose, she could sit gazing out of the window. (ibid. 111)

Las masas son constantemente expuestas a los mismos objetos de deseo que le son negados, y crea así la promesa de una satisfacción que no llegará; ahí radica el poder social de la industria cultural:

The culture industry endlessly cheats its consumers out of what it endlessly promises. The promissory note of pleasure issued by plot and packaging is indefinitely prolonged. [...] The culture industry does not sublimate: it 
suppresses. By constantly exhibiting the object of desire. The breast beneath the sweater, the naked torso of the sporting hero, it merely goads the unsublimated anticipation of pleasure, which through the habit of denial has long since been mutilated as masochism. [...] the culture industry is pornographic and prudish. It reduces love to romance... (ibid. 112)

Tiene, además, la capacidad de hacer a las masas olvidar su sufrimiento:

The more strongly the culture industry entrenches itself, the more it can do as it chooses with the needs of consumers -producing, controlling, disciplining them; even withdrawing amusement altogether: here no limits are set to cultural progress. [...] But the original affinity between business and entertainment reveals itself in the meaning of entertainment itself: as society's apologia. To be entertained means to be in agreement. Entertainment makes itself possible only by insulating itself from the totality of the social process, making itself stupid and perversely renouncing from the first the inescapable claim of any work, even the most trivial: in its restrictedness to reflect the whole. Amusement always means putting things out of mind, forgetting suffering, even when it is on display. At its roots is powerlessness. It is indeed escape, but not, as its claims, escape from bad reality but from the last thought of resisting that reality. The liberation which amusement promises is from thinking as negation. (ibid. 115)

Estas son algunas ideas que informan teóricamente la lectura de Rivera en YouTube, que se observa aquí como una expresión de la industria cultural, empleada para mantener los intereses de una élite del poder, representada por la pareja presidencial. Al acudir a una argumentación y una producción audiovisual similares a las de una telenovela, el video de YouTube apela a una cultura unificada instaurada en la sociedad; al retratar a la «Primera Dama» mediante elementos asociados a su papel protagónico de 2007, este video parece constituir una extensión de ese ejercicio en el que, a través de sus contenidos, la industria cultural promete a las masas la satisfacción de deseos que no se llevarán a cabo. Finalmente, el contenido ideológico, que viaja desde la telenovela de 2007 a la defensa de 2014, habla también de una estrategia que utiliza una estética que opera en YouTube como entretenimiento televisado.

\subsection{Premisas de la argumentación: el acuerdo, los valores y su jerarquía}

De acuerdo con la nueva retórica propuesta por Perelman y OlbrechtsTyteca (1969), el orador u oradora interesado(a) en generar un efecto o cambio en la audiencia, debe, en principio, adaptarse a esta y cualquier adaptación de la oradora con respecto a la audiencia repercutirá en modificaciones a su discurso. Consideramos que la propuesta de Perelman y 
Olbrechts-Tyteca permite establecer un puente tanto con la perspectiva glotopolítica mencionada en $\S 1$, en tanto la nueva retórica, en lo general, parte de la argumentación como proceso discursivo de persuasión y, por lo tanto, de naturaleza predominantemente política, como con las ideas de Horkheimer y Adorno, en tanto comparten una visión no formalista de la lengua; las tres contribuciones, además, destacan el aspecto social de la lengua. Perelman y Olbrechts-Tyteca (1969), detallan que:

Our procedure will differ radically from that adopted by those philosophers who endeavor to reduce reasoning in social, political, and philosophical matters by taking their cue from the models provided by deductive or experimental sciences, and who reject as worthless everything which does not conform to the schemes which were previously imposed [...] we seek here to construct such a theory by analyzing the methods of proof used in the human sciences, law, and philosophy. We shall examine arguments put forward by advertisers in newspapers, politicians in speeches, lawyers in pleadings, judges in decisions, and philosophers in treatises. (Perelman y Olbrechts-Tyteca 1969: 10)

Para que en la argumentación pueda existir un «contacto entre las mentes» entre la oradora y su audiencia, establecen los autores, deben darse algunas condiciones preliminares, entre las que mencionan: la existencia de una «lengua común»", la pertenencia a una misma clase, el «intercambio de visitas» $y$ «otras relaciones sociales» (cf. p. 17). Dadas estas condiciones preliminares, la argumentación, entendida como el proceso verbal mediante el cual el orador busca persuadir a una audiencia, inicia con la presuposición de que el primero cuenta con el acuerdo (agreement) de la segunda; es decir, parte de la creencia, confianza o certeza de que los destinatarios del mensaje aceptan o aceptarán las ideas, el desarrollo y el ordenamiento del discurso que lo transporta:

... this agreement is sometimes on explicit premises, sometimes on the manner of using those links: from start to finish, analysis of argumentation is concerned with what is supposed to be accepted by the hearers $[\ldots]$ the actual choice of premises and their formulation [...] are rarely without argumentative value: it is a preparation for argument which not only establishes the elements but constitutes the first step in the utilization of those elements for persuasive purposes. (Perelman y Olbrechts-Tyteca 1969: 65)

${ }^{8}$ Esta condición previa del llamado «contacto entre las mentes» resulta, a nuestro parecer, problemática, pues el mero hecho de compartir una lengua «común» no es garantía de comunicación para el intercambio de argumentos. La argumentación en ámbitos académicos, por ejemplo, parece requerir capitales que rebasan el ámbito de lo estrictamente lingüístico, y de igual forma en otras esferas de interacción, es la ostentación y apropiación de otros códigos/registros, sociales y simbólicos, los que también posibilitan un acceso al diálogo. 
Así, la oradora selecciona y adelanta las premisas que considera servirán como base de su argumentación, confiando en que los destinatarios estarán de acuerdo con estas. No obstante, en ocasiones las premisas de partida pueden ser rechazadas por la audiencia, ya sea porque considere que están sesgadas, o porque las perciba como tendenciosas en la forma en que se desarrollan. Cuando este es el caso, el rechazo a las premisas, sostienen Perelman y Olbrechts-Tyteca, puede darse por medio de la crítica a tres de sus aspectos: su aceptación, su selección y su presentación.

El presente trabajo se detiene en el aspecto relacionado con los tipos de objeto para generar acuerdo (aceptación/rechazo), tomados como premisas de una argumentación que pretende persuadir al auditorio de que Angélica Rivera no es culpable del presunto tráfico de influencias en la construcción de su casa, elaborando, además, la imagen de mujer independiente, trabajadora, honrada y transparente, como pruebas que demuestran su inocencia. En particular, se abordan los tipos de acuerdos que los autores identifican como «valores», «jerarquías» $\mathrm{y}$ «lugares comunes» (loci), identificados por Perelman y Olbrechts-Tyteca como aquellos que se encuentran en el ámbito de «lo preferible», los cuales van dirigidos a una audiencia específica, que en este caso corresponde a la sociedad mexicana imaginada por la oradora, en oposición a aquellos tipos de acuerdos que se dirigen a una audiencia universal, clasificados por los autores como «hechos», «verdades» o «supuestos», ubicados en el ámbito de «lo real». Siguiendo la propuesta de estos autores, y sin pretender una problematización de estas categorías, nos limitamos a definir los objetos de acuerdo que persiguen a la audiencia universal (hechos, verdades, supuestos), como aquellos que gozan de un estatus de acuerdo incuestionable y universal ${ }^{9}, \mathrm{y}$ a los objetos de acuerdo que persiguen a una audiencia particular o específica (valores, jerarquías y loci), como aquellos orientados a influenciar hacia una acción o disposición a una acción, aunque el punto de vista representado no se encuentre relacionado con el de todos los integrantes de dicha audiencia. Los valores, apuntan los autores, aparecen en todo tipo de argumentación, en algún momento u otro:

In reasoning of a scientific nature, they are generally confined to the beginning of the formulation of the concepts and rules $[\ldots]$ and $[\ldots]$ to the conclusion. As far as possible, the actual unfolding of the argument is free from values, and this exclusion is at a maximum in the exact sciences. But in the fields of law, politics, and philosophy, values intervene as a basis for argument at all stages of the developments. One appeals to values in order

\footnotetext{
${ }^{9}$ Los autores reconocen, no obstante, el carácter inestable de la categoría «hecho», el cual, en razón de encontrarse atado a una determinada audiencia, no tiene asegurado su estatus como tal.
} 
to induce the hearer to make certain choices rather than others $[\ldots]$ to justify those choices that they may be accepted and approved by others. (Perelman y Olbrechts-Tyteca 1969: 75)

Acudimos a esta noción de «valor» ya que nos permite estudiar los temas que, explícita o implícitamente, Rivera emplea para dirigirse a su audiencia y persuadirla. Desde la clasificación de Perelman y Olbrechts-Tyteca, se puede adelantar que los argumentos que presenta la actriz son tomados por esta como principios de acuerdo, al asumir que su audiencia los compartirá. Estos valores parecen hacer eco de aquellos que pueden identificarse en telenovelas de producción reciente en México, entre las que se encuentra la que ella misma protagonizó, Destilando amor. La apuesta política que Rivera hace con esta argumentación consistiría en retomar estos valores, partiendo de asumirlos como objeto de acuerdo entre la audiencia, los mexicanos, para construir con estos el supuesto de que su exhibición es prueba irrefutable de su inocencia en el caso de corrupción en el que está presuntamente implicada.

La clasificación de valores de Perelman y Olbrechts-Tyteca establece una distinción entre valores abstractos y valores concretos. Esta división, no obstante, no es fija, pues en ocasiones «lo abstracto» puede ser tomado como «concreto» y viceversa; esta naturaleza ambigua permite a los valores ser resignificados, o redefinidos, según el programa político del orador u oradora. Al respecto, los autores explican que el proceso mediante el cual un valor «abstracto» es transformado a uno «concreto» implica atribuirle a este cierta especificidad o unicidad; dicho proceso constituye la toma de una postura arbitraria ${ }^{10}$ en tanto demanda adoptar una descripción o definición del valor en cuestión. Como ejemplo, el concepto «pueblo» conllevaría un carácter abstracto en una expresión como «la explotación del pueblo», y uno concreto en una como «Uruapan es el pueblo donde nací». Según los autores, el uso de valores abstractos se encuentra vinculado a un espíritu de cambio, «they seemingly manifest a revolutionary spirit» (ibid. 79), en tanto están sujetos a mayor criticismo, mientras que "where change is not wanted, there is no reason to raise incompatibilities» (ibid.), $\mathrm{y}$, al respecto, continúan:

Leaning on concrete values would thus be much easier when one wishes to preserve than when one wishes to renovate. The reason conservatives consider themselves realists is perhaps that they put these values in the foreground. The notions of fidelity, loyalty, and solidarity, which are

${ }^{10}$ Es importante hacer notar cómo este proceso semiótico en la argumentación, tratado por Perelman y Olbrechts-Tyteca, encuentra semejanzas con la idea saussureana de la arbitrariedad en la relación entre significante y significado. 
connected with concrete values, do in fact often characterize conservative argumentation. (ibid.)

Esta posibilidad de resignificación según las intenciones políticas de la oradora ofrece nuevas definiciones sobre lo que se entiende sobre algún valor en especial: "An intense activity in the realm of values is thereby made possible; they are constantly being recast and remodeled» (ibid.). La conceptualización de los valores propuesta por Perelman y OlbrechtsTyteca permite observar que, ya sean abstractos o concretos, y al margen de su flexibilidad como significantes, estos se entrecruzan creando jerarquías en la argumentación, organizándose estratégicamente según las intenciones comunicativas.

Efectivamente, más allá de clasificar los valores en abstractos o concretos, los autores apuntan que la jerarquización que el orador u oradora haga de ellos resulta de mayor valor para entender el ejercicio de argumentación:

Value hierarchies are, no doubt, more important to the structure of an argument than the actual values. Most values are indeed shared by a great number of audiences, and a particular audience is characterized less by which values it accepts than by the way it grades them. (ibid. 81)

De tal forma, ciertas argumentaciones tenderán a privilegiar jerarquías de lo real ${ }^{11}$ y otras lo harán hacia jerarquías de lo preferible ${ }^{12}$. En cualquier caso, en el desarrollo de la argumentación ambos esquemas aparecen entrecruzados, y es por este motivo que deben ser estudiados en su conjunto, como una jerarquía de valores. Los valores que presenta Angélica Rivera en su defensa de YouTube se presentan resignificados y en relaciones subordinadas en una jerarquía no explícita que debe analizarse y explicarse, sin caer en el «monismo de valores» (ibid. 82), es decir, una aproximación aislada a estos.

Otra forma de observar este sistema de valores apuntalado por Rivera puede ser la categoría de «lugares comunes», referidos en el tratado de la argumentación de Perelman y Olbrechts-Tyteca como loci, entendidos como premisas de una naturaleza muy general: «we shall only apply the term loci to premises of a general nature that can serve as the bases for values and hierarchies» (1969: 84). A pesar de que los autores rehúsan elaborar una tipología exhaustiva de los loci, apuntan que:

11 Algunos discursos, por ejemplo, destacan el grado de veracidad de ciertos datos o fenómenos, aunque socialmente «carezcan» de importancia.

12 Discursos que dan mayor importancia a la relevancia y aplicación social de una investigación, por encima de la confiabilidad de sus hallazgos, por ejemplo. 
Our concern is with the fact that all audiences, of all kinds, have to take loci into account. We will classify loci under a few very general headings: loci of quantity, quality, order, the existing, essence, and the person. (Perelman y Olbrechts-Tyteca 1969: 85)

Perelman y Olbrechts-Tyteca reconocen que estos loci pueden ser reducidos solo a dos: cantidad y calidad. Así, en sus aspectos argumentativos generales, la actriz mexicana acude a los loci de calidad, en tanto busca resaltar su carácter de unicidad, al cual opone lo ordinario, lo común o lo vulgar (cf. p. 90), y de persona, en tanto pretende destacar su dignidad (el honor personal) y su autonomía, así como conferir valor «on that which is done with care and demands effort» (ibid. 95), como lo es su compromiso hacia el trabajo.

A pesar de las posibilidades de caracterización que ofrece este concepto, Perelman y Olbrechts-Tyteca aseguran que los loci más comunes (cantidad, calidad, orden, existencia, esencia y persona) son finalmente el resultado de valores y jerarquías y que en la medida en la que esos loci se vuelven más específicos se da un cambio gradual e imperceptible hacia «those agreements which we would prefer to consider as agreements on values or hierarchies» (ibid. 95). Por este motivo, aunque en rasgos generales es posible identificar que la argumentación de Angélica Rivera emplea lugares comunes de calidad y persona, y con la intención de evitar confusión terminológica, estos loci son desintegrados aquí y tratados en su calidad de «valores». Siguiendo estas propuestas conceptuales, en el siguiente análisis se emplea el término «valor», en el entendido de que es en buena medida equivalente al de loci. Sin enunciarla, los autores dibujan la idea de que todo valor es loci, o que todo loci es resultado de la extensión o generalización de un valor o conjunto organizado de valores.

\section{MATERIAL}

A continuación, se presenta una transcripción del video de Rivera en YouTube. La segmentación en enunciados se realizó a partir de la identificación de unidades con cierta independencia comunicativa y según su función en relación con el evento discursivo total. El video se titula «Precisiones sobre la propiedad de Sierra Gorda 150 - Sra. Angélica Rivera de Peña» ${ }^{13}$.

En la transcripción, las pausas de silencio están marcadas con el símbolo (/), convención empleada por el Proyecto para el Estudio Sociolingüístico del Español de España y América (PRESEEA) (2008, en línea), cada una

\footnotetext{
$13<$ https://www.youtube.com/watch?v=tdJ06CLjjxE $>$.
} 
equivale a una duración aproximada de un segundo. Rivera sostiene un legajo de hojas y simula alternar entre la lectura de estas y la enunciación espontánea en momentos en que voltea a ver a la cámara. Mirar directamente a esta se considera una estrategia para enfatizar los enunciados; estos momentos se indican con letras itálicas en la transcripción, mientras los casos de lectura aparecen sin el realce en itálicas. El video presenta seis cortes con acercamientos y alejamientos de cámara que alternan entre el plano medio (encuadre a partir de la cintura) y el primer plano (o close$u p$, la cámara se acerca y encuadra desde los hombros). Se asume que los close-ups son recursos de la producción audiovisual que también contribuyen a dar realce a los elementos del discurso que enmarcan. Los cortes de cámara se señalan entre corchetes en la transcripción.

(1) Muy buenas noches /

(2) hoy he decidido dirigirme a todos los mexicanos / porque ustedes / tienen el derecho de conocer la verdad //

(3) yo no tengo nada que esconder /

(4) como ciudadana / aún sin ser servidora pública / me siento con la responsabilidad / de explicarles paso a paso / todo lo relacionado con la casa / que ha sido cuestionada por algunos medios de comunicación //

- [corte de video - alejamiento de cámara]

(5) quiero empezar agradeciendo / al licenciado Eduardo Sánchez vocero del Gobierno de la República / que en mi ausencia / mientras viajaba a China para acompañar a mi esposo a una gira de trabajo / haya adelantado algunas explicaciones sobre la casa ubicada en Sierra Gorda / número ciento cincuenta /

(6) al tratarse de un tema estrictamente personal / no contó con toda la información necesaria / para explicar en su totalidad este asunto / por ello el día de hoy quiero ampliarles esta información / y hacer algunas precisiones ///

(7) inicié mi carrera artística desde los 15 años / trabajé 25 años con la empresa Televisa / entre otras cosas realicé telenovelas / que no solamente fueron vistas en México / sino en muchos otros países del mundo / con una alta audiencia /

(8) con esta empresa / he celebrado distintos contratos / a lo largo de mi carrera / la última renovación de estos contratos / fue en el año 2004 / en $m i$ caso en cada renovación los montos y las prestaciones de los mismos / tenían un incremento / derivado de los resultados de mi trabajo /

(9) en el marco de dicho contrato con Televisa / en el año dos mil ocho se me otorgó el uso y goce de la casa ubicada / en Paseo de Las Palmas número mil trescientos veinticinco y comencé a vivir en ella en ese mismo año / 
(10) el contrato que firmé en el dos mil cuatro / lo dimos por terminado de mutuo acuerdo Televisa y yo / el veinticinco de junio del dos mil diez / y en el mismo / se impusieron / obligaciones / a ambas partes / que describo a continuación //

(11) el veinticinco de junio del dos mil diez / se me pagó con la propiedad de la casa que ya habitaba / es decir / la casa / de Paseo de Las Palmas / la escritura de esta casa se expidió a mi favor / el catorce de diciembre / del dos mil diez / además de la casa se me pagó / un monto total / de ochenta y ocho millones seiscientos treinta y un mil pesos más IVA /

- [corte - acercamiento de cámara]

(12) para dar por terminado el contrato / me comprometí con la empresa Televisa a no trabajar con ninguna otra televisora por el plazo de cinco años / esto se tomó en cuenta / para determinar / el monto del contrato ///

(13) asi // les demuestro que tengo la capacidad económica / y recursos propios / que me han permitido construir un patrimonio / para mi / y para mis hijas /

- $\quad$ corte - alejamiento de cámara]

(14) en mi declaración fiscal del dos mil diez / año en el que celebré el convenio de terminación con Televisa / declaré ante Hacienda / ingresos por la cantidad de ciento treinta y un millones seiscientos noventa mil pesos / y pagué por impuestos / en ese año / la cantidad de treinta y nueve millones doscientos setenta y ocho mil pesos /

(15) reitero que más allá de este contrato / trabajé 25 años en el medio artístico / como actriz / conductora / y además realicé diferentes campañas de publicidad / por los cuales / he recibido los pagos / producto de mi trabajo /

(16) para continuar forjando un patrimonio para mis hijas / en el dos mil nueve inicié la búsqueda de un terreno para construir una casa //

- [corte - acercamiento de cámara]

(17) Efectivamente / conoci al ingeniero Juan Armando Hinojosa / como he conocido a muchos otros empresarios / profesionistas / artistas y otras personas //

(18) por las actividades inmobiliarias / a las que se dedica / le comenté que quería adquirir un terreno / y construir una casa /

(19) acordamos que una de sus inmobiliarias / adquiriera un terreno / y construyera / la casa a mi gusto / y con el arquitecto / de mi elección / yo me comprometi / a que una vez / que se terminara la construcción de la casa / celebrariamos un contrato de compra-venta / 


\section{- [corte - alejamiento de cámara]}

(20) la inmobiliaria / consiguió y adquirió / en noviembre del dos mil nueve / el terreno de Sierra Gorda / número ciento cincuenta // que está junto a mi casa de Palmas /

(21) se inició la construcción de la casa / en el mes de julio / del dos mil diez / tiempo después la inmobiliaria / me comentó / que el terreno de junto estaba en venta / y se acordó que se compraría / para integrarlo / a la casa / que estaba en construcción //

(22) una vez concluida la casa / el doce de enero del dos mil doce / firmé con la inmobiliaria / una compra-venta con reserva de dominio / respecto / a los inmuebles fusionados / con número ciento cincuenta y ciento sesenta de la calle Sierra Gorda / así como en relación / con las construcciones en ellas edificadas // en esa fecha / se me dio formalmente la posesión /

(23) el total del precio de la compra-venta fue / de cincuenta y cuatro millones de pesos / a un plazo de ocho años / con un interés del 9 por ciento // al día de hoy / he pagado un total / de catorce millones / trescientos cuarenta $\mathrm{y}$ tres mil quinientos cincuenta y cinco pesos / monto que equivale / casi / a un treinta por ciento / del total / del precio pactado //

(24) la casa y las construcciones / siguen siendo propiedad de la inmobiliaria / hasta que yo haga el pago total / del precio pactado y de todos sus intereses /

(25) por último / y para evitar cualquier especulación / hago público / que además soy propietaria desde el dos mil cinco / de un departamento en Miami / ciudad en la que viví durante un año con mis hijas / así como un departamento en La Herradura / que adquirí para mi mamá en el dos mil siete /

(26) ante todas las acusaciones que han puesto en duda mi honorabilidad / yo quiero dejar muy claro ante todos ustedes / los mexicanos / que yo no tengo nada que esconder /

(27) que yo he trabajado toda mi vida / y que gracias / gracias a eso soy una mujer independiente / que he sido capaz / de construir / un patrimonio con honestidad / y con todo mi trabajo //

(28) siempre me he conducido / con rectitud / y por eso / decidi explicarles / todo lo relacionado con esta casa /

\section{- [corte - acercamiento de cámara]}

(29) con la misma apertura / con la que les he compartido los detalles de esta casa / quiero comunicarles que he tomado la decisión / de vender los derechos / derivados del contrato de compra-venta / porque / yo no quiero que esto siga siendo / un pretexto / para ofender / y difamar a mi familia / 
(30) hoy estoy aqui // para defender mi integridad / la de mis hijos / y la de mi esposo / junto a esta explicación que les he dado / en este momento // yo estoy haciendo pública documentación privada // sin tener ninguna obligación / porque como lo dije antes / yo no soy servidora pública / pero / yo no puedo permitir que este tema / ponga en duda mi honorabilidad / y sobre todo / que se pretenda dañar a mi familia / buenas noches.

\section{ANÁlisis}

A partir de este material, el análisis pretende ofrecer una lectura que relaciona los valores argumentativos de Rivera en YouTube con un producto de la industria cultural en México, la telenovela, y mostrar cómo esta relación se refleja en este uso de la lengua.

\subsection{Estructura argumentativa}

De acuerdo con Perelman (1982: 146), las partes de un discurso que pretende conseguir la aceptación de un auditorio son Exordio, Narración, Demostración, Refutación, Recapitulación y Peroración. Estas partes no constituyen un orden fijo, sino que se adaptan según la audiencia y los propósitos discursivos. Para los efectos analíticos de este trabajo, la argumentación de Rivera se ha dividido de la siguiente manera: Exordio: líneas (1) a (4); Narración: líneas (5) a (25). Al interior de la Narración se identifican una Demostración: líneas (12) a (15), y dos Refutaciones, la primera entre las líneas (17) y (19), la segunda en (23) y (24); el Epílogo comienza en (26) y contiene una Recapitulación de (26) a (28), y una Peroración en (29) y (30) (ver Tabla 1).

TABLA 1. Estructura argumentativa del discurso de Angélica Rivera en YouTube

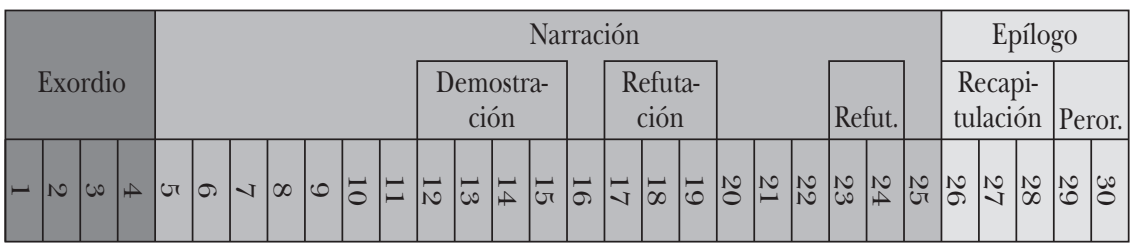

En las imágenes de la siguiente página se aprecian las alternancias entre momentos de lectura y enunciación enfática, así como planos medios y close-ups. 


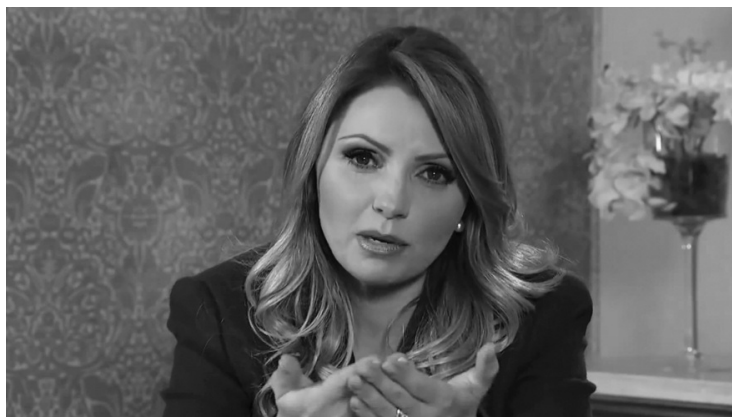

Figura 1. Exordio.

«Me siento

con la responsabilidad de explicarles, paso a paso, todo lo relacionado con la casa que ha sido cuestionada por algunos medios de comunicación»

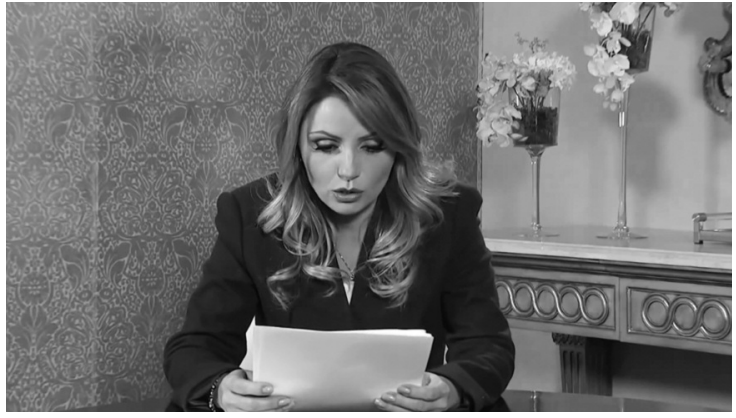

Figura 2. Narración.

«La escritura de esta casa se expidió a mi favor el 14 de diciembre del 2010»

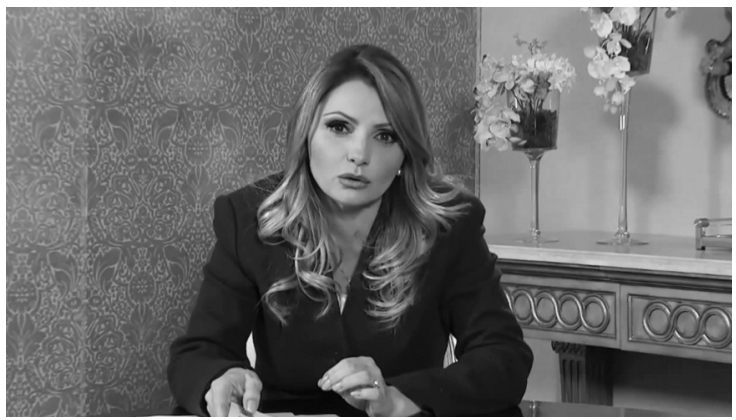

Figura 3. Recapitulación. «Siempre me he conducido con rectitud»

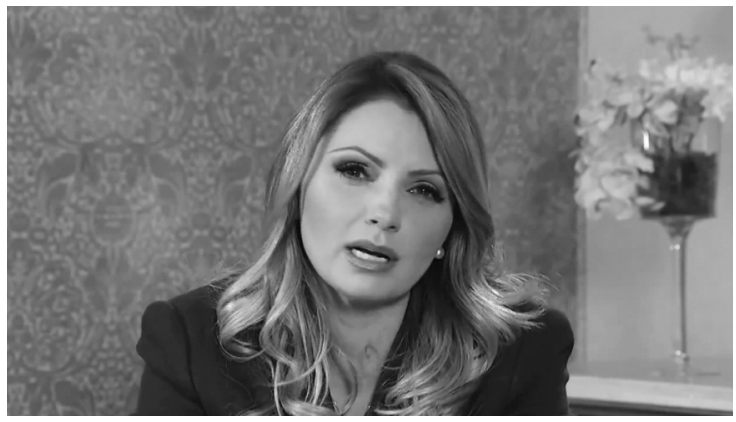

Figura 4. Peroración. «Yo estoy haciendo pública documentación privada, sin tener ninguna obligación» 


\subsection{El acto supererogatorio}

El análisis del video puede partir de la pregunta sobre cuál es el propósito del mensaje de Rivera. Para entender el sentido de su aparición pública, es necesario acudir a la importancia sociopolítica del caso, la producción audiovisual del video, los recursos técnicos y humanos que requirió para su realización y el orden y contenido argumentativo presentados en él.

En primer lugar, hay que hacer notar que la totalidad del evento discursivo pretende funcionar por sí mismo como un acto supererogatorio, esto es, Rivera busca convencer a su audiencia de que dar estas explicaciones de forma pública es en sí mismo un acto que debería ser valorado como excepcionalmente positivo, dado que ella, al no ser servidora pública, no se encuentra legalmente obligada a hacerlo. Efectivamente, ninguna ley la obliga a explicar cómo ha adquirido sus bienes patrimoniales, pues la esposa del presidente es vista por el aparato estatal como una ciudadana ordinaria. Entonces, ¿por qué lo hace? Las razones que esgrime son que «no tiene nada que esconder» y que quiere "defender» a su familia de las injustas acusaciones. El orden lógico de estos argumentos parece ser: en tanto ella no ha hecho nada impropio, en tanto es una persona «honorable», «da la cara» para ofrecer una explicación pública. En este acto supererogatorio, está anclado uno de los valores que Rivera usa como una de sus cartas fuertes: el ser una ciudadana como cualquiera otra, que ha trabajado para construir un patrimonio familiar. Rivera emplea así el acto supererogatorio como medio para conseguir la empatía de la audiencia, «los mexicanos», a través del cual alude a temas/valores con los que ella estima que la sociedad podría identificarse (el trabajo arduo y constante, la familia, la honestidad), los cuales formarían parte de una estructura de valores o sentimientos comunes empleados para ganar credibilidad.

La premisa parece ser «no tengo nada que esconder» por lo tanto «doy la cara para explicar el caso» («aunque nada me obliga, ni nadie me pide hacerlo»), que apuesta por ser un argumento de especial fuerza en el discurso de la actriz. El acto supererogatorio se enfatiza en los enunciados (4) y (30), que coinciden con el Exordio y la Peroración, respectivamente, lo que coincidiría con lo que Perelman (1982) denomina un orden de tipo «homérico», en el que los argumentos más sólidos son llevados al principio $y$ al final del discurso (p. 148).

Este acto supererogatorio, no obstante, impregna todo el video. Sin mencionarlo explícitamente, muchos otros enunciados $(4,10,11,17,20$, $21,22,23,24,25,28,29$ y 30 en $§ 3)$, se orientan hacia ese acto, consistente en explicar algo que la actriz no considera que está obligada a explicar. Estos enunciados pueden ser vistos como una parte central del discurso de Rivera en tanto constituyen menciones dispersas a lo largo de todas las 
secuencias argumentativas propuestas en la Tabla 1. Además del hecho de constituirse como un acto excepcionalmente bueno, la publicación del video en YouTube representa un supuesto replanteamiento de la comunicación política que las élites del gobierno mantienen con la sociedad, pues al ser Rivera una ciudadana ordinaria pudo haberse quedado callada, sin embargo no lo hizo. Esta voluntad podría indicar una necesidad percibida por el gobierno de construir una imagen de cercanía con la sociedad, a través de un medio no convencional, aunque también respondería a una cultura de la transparencia y la rendición de cuentas, fuertemente promovida en México durante los últimos veinticinco años.

\section{3 «Valores» en el video de YouTube}

\subsubsection{El trabajo}

Un argumento recurrente en la defensa de Angélica Rivera es el trabajo, el cual presenta como un valor personal al que alude especialmente en la Narración, y que retoma en la Peroración. Los enunciados (7), (8), (13), (15) y (27) lo muestran más claramente en expresiones como: «inicié mi carrera artística desde los 15 años», «trabajé 25 años con la empresa Televisa», «los montos y las prestaciones de los mismos [los contratos], tenían un incremento derivado de los resultados de mi trabajo», "he recibido los pagos, producto de mi trabajo», «yo he trabajado toda mi vida, y que gracias, gracias a eso soy una mujer independiente».

El hecho de que el valor atribuido al trabajo constante, en especial aquel orientado a construir un patrimonio para los hijos, aparezca en la Narración y luego en la Recapitulación final del Epílogo, indica la importancia de este argumento en Rivera para defender su honor ante las acusaciones de corrupción por tráfico de influencias. Se trata de un andamio discursivo fundamental pues, además de emplearlo para presentarse como una persona honorable, pretende constituirse como estrategia para conseguir la adhesión de un auditorio en el que se proyecta la totalidad de la nación. Detrás de esta valoración hacia el trabajo como premisa de acuerdo, identificamos un predicado implícito en la producción del video: en la más alta esfera del poder en México, es decir, la familia presidencial, así como en el equipo de comunicólogos, estrategas y asesores que pudieron haber participado en la producción del video, existe consciencia de que la mayoría de los mexicanos son de clase trabajadora y deben trabajar «arduamente» para poder mantener a sus familias. El mensaje subyacente puede ser interpretado como «soy igual que todos, y como todos debo trabajar y comprar una casa en mensualidades». 
Esta estrategia de victimización por explotación y sometimiento laboral resulta ingenua por parte de Rivera, pues la mayor parte del auditorio al que se dirige, si bien trabaja para «construir un patrimonio» y se endeuda con una hipoteca, como lo hizo ella, nunca podrá comprar una casa de 54 millones de pesos (2,9 millones de dólares a fines de $\left.2015^{14}\right)$. Esta falla argumentativa en el discurso de la actriz pudo haber sido uno de los elementos que desencadenaron críticas y burlas en varios medios, y podría ser también una de las razones por las que el video publicado en su cuenta personal de YouTube no está abierto a la publicación de comentarios por parte de los internautas.

\subsubsection{La familia}

Otro pilar argumentativo desarrollado por Rivera es la familia. Este valor se aprecia inicialmente en los enunciados (13) y (16). La expresión «así, les demuestro que tengo la capacidad económica y recursos propios que me han permitido construir un patrimonio para mí y para mis hijas» en (13), aparece tras posicionamientos sobre el trabajo como pilar de su justificación. El valor del trabajo, por lo tanto, se aprecia encadenado con la familia como valor abstracto, y con la madre y las hijas, como valor concreto. El enunciado "para continuar forjando un patrimonio para mis hijas, en el 2009 inicié la búsqueda de un terreno para construir una casa» en (16), liga nuevamente el valor de la familia al del trabajo.

Estas configuraciones retóricas vuelven a aparecer al inicio del Epílogo, en (25), donde aclara que «para evitar cualquier especulación, hago público que además soy propietaria desde el 2005, de un departamento en Miami, ciudad en la que viví durante un año con mis hijas», "así como de un departamento en La Herradura que adquirí para mi mamá en el 2007». En estos dos enunciados, Rivera alude al «bienestar familiar» o la familia como estrategia atenuadora de su riqueza personal: la posesión de un departamento en Miami se justifica porque vivió ahí con sus hijas, y la posesión de un departamento en La Herradura se justifica con la figura materna. La explicación resulta circular: «proteger», «mantener» o «apoyar» a la familia no implica necesariamente la compra de bienes inmuebles.

Resulta conveniente hacer una puntualización aquí. Los ejemplos (13), (16) y (25) se ubican en una secuencia cronológica de acontecimientos en la que Rivera se autorrepresenta primero como una madre soltera. Cuando habla de «sus hijas» en estos tres ejemplos, se refiere a la prole que engendró de su primer matrimonio, de 1994 a 2008. Es también por esta razón

14 Tipo de cambio MXN/USD correspondiente a octubre de 2015. 
que, en ese contexto, las referencias al trabajo constante y el énfasis en construir un patrimonio se posicionan como focos principales, pues coinciden en el plano temporal con su etapa de madre soltera desde 2008 hasta finales de 2011, año en el que contrajo matrimonio con Enrique Peña Nieto. Conforme avanza el hilo narrativo hacia hechos posteriores a $2011 \mathrm{y}$ hacia el presente (que para el caso es noviembre de 2014, fecha de realización y publicación del video en YouTube), se observa que las referencias a la familia han sufrido un cambio en el género gramatical: de «hijas» pasa al masculino universal «hijos». Peña Nieto enviudó de un primer matrimonio con el que engendró tres hijos, entre ellos un varón. Al casarse Rivera y Peña en 2011 la familia se expandió, este hecho explica el cambio de «hijas» que se presenta durante casi todo el video a «hijos», en (30): «hoy estoy aquí para defender mi integridad, la de mis hijos y la de mi esposo», donde hijos refiere a la suma de descendientes de ambos, cuatro mujeres y un hombre. Este cambio gramatical no solo representa un suceso particular en la vida personal de la actriz (el paso de madre soltera a mujer casada), sino que permite observar una ideología liberal que resignifica el concepto de familia, de lo abstracto a lo concreto, entendida como una unión más allá del lazo consanguíneo y las convenciones tradicionales del catolicismo. Este cambio hace, por lo tanto, un guiño a la compleja composición social de la familia moderna, que por sutil que parezca resulta políticamente relevante. De este hecho, resulta productivo preguntar cuál es el conocimiento subyacente que la actriz y los posibles productores e involucrados en la realización del video asumen que se encuentra en la audiencia como para confiar en que estos gestos liberales serán artefactos efectivos para convencer y sumar adeptos.

Las últimas líneas en la Peroración contienen también una alusión a la familia como soporte del discurso de Rivera. El enunciado (30) es la coda del mensaje: «yo no puedo permitir que este tema ponga en duda mi honorabilidad, y sobre todo, que se pretenda dañar a mi familia». La actriz publica este video en un tono de indignación y molestia ${ }^{15}$, tono que corresponde como reacción «natural» ante las falsas e injustificadas acusaciones hacia ella y su familia.

\subsubsection{El honor}

En los siete minutos y once segundos de duración del video, aparecen referencias al «deber ser», la moral, los compromisos asumidos, el honor. Demostrar la congruencia o relación entre lo que se es y lo que se dice ser constituye una de las mayores pruebas que el inocente puede presentar

${ }^{15}$ Un análisis entonativo es una tarea que rebasa el propósito de este trabajo. 
ante cualquier tribunal. Rivera quiere posicionarse como una persona recta: la expresión «siempre me he conducido con rectitud, y por eso, decidí explicarles todo lo relacionado con esta casa", aparece en la Recapitulación (28). Y enseguida, en la Peroración: «Hoy estoy aquí para defender mi integridad» $\mathrm{y}$ «yo no puedo permitir que este tema ponga en duda mi honorabilidad», en (30). En efecto, la frase "yo no tengo nada que esconder» aparece repetida en el Exordio (3) y en la Recapitulación (26), esta distribución de argumentos nos lleva a plantear nuevamente que se trata de un valor central en el discurso de Rivera. El honor viene también de la mano con el trabajo (v. supra). La actriz «da la cara» pues no tiene nada de qué avergonzarse, sino por el contrario, está orgullosa de que ha trabajado duro y por eso ha podido comprar sus propiedades.

Rivera construye una imagen propia, hace un face-work (Goffman 1967), en la que se presenta como persona «de palabra», esto se aprecia en todo el video, pero principalmente en la secuencia narrativa, a través de elementos que se relacionan o van de la mano con el trabajo. Por ejemplo, en (12) refiere un compromiso asumido con «la empresa Televisa»: «me comprometí con la empresa Televisa a no trabajar con ninguna otra televisora por el plazo de cinco años»; esta información resulta secundaria en la defensa de Rivera y aporta valor solo en función de que representa el respeto hacia un compromiso asumido, es decir, el cumplimiento de la palabra. Llama la atención la expresión «la empresa Televisa», epíteto que corresponde a un estilo formal, cuya solemnidad hace parte de la estrategia persuasiva; es decir, no es sencillamente «Televisa», bien conocida en México y Latinoamérica, sino «la empresa Televisa».

En una línea similar, en (14) Rivera destaca que «en mi declaración fiscal del 2010 [...] declaré ante Hacienda, ingresos por la cantidad de 31 millones 690 mil pesos, y pagué por impuestos, en ese año, la cantidad de 39 millones 278 mil pesos»; se observan aquí no únicamente el lenguaje técnico y las precisiones numéricas como recursos retóricos, sino también una oportunidad tomada para recordar que declara y paga impuestos, lo que coincide con un discurso de la rendición de cuentas, de mayor complejidad en el plano de la vida política nacional, y que aquí queda expresado en la importancia de contar con una trayectoria fiscal intachable, como cualidad que debe tener toda buena ciudadana, como ella es. El hecho de declarar impuestos y nombrarlo con la «naturalidad» con que la actriz lo hace, hacen parte de un juego verbal que le permite introducir frases numerales para contribuir a un registro técnico, preciso, «objetivo», más «creíble».

Los enunciados (19), (23), (24), (26), (28) y (30) representan otros casos de este face-work de persona honorable, respetuosa de acuerdos, que Rivera realiza. Algunas de las expresiones que aquí aparecen son: "yo me comprometí a que una vez que se terminara la construcción de la casa, 
celebraríamos un contrato de compra-venta», «la casa y las construcciones, siguen siendo propiedad de la inmobiliaria, hasta que yo haga el pago total», y «al día de hoy he pagado un total de 14 millones 343 mil 555 pesos, monto que equivale casi a un treinta por ciento del total del precio pactado».

\subsubsection{La mujer}

En el sistema de valores expuesto, se encuentra también la construcción de una identidad de género como parte del ejercicio argumentativo para persuadir a los mexicanos. En (27), en la Recapitulación, la actriz establece "que yo he trabajado toda mi vida, y que gracias, gracias a eso soy una mujer independiente, que he sido capaz, de construir un patrimonio con honestidad y con todo mi trabajo». Este enunciado sintetiza el peso de los valores antes expuestos (el trabajo, la familia, el esfuerzo, el compromiso, el honor, la honestidad), y muestra cómo se encuentran atravesados por la idea de «mujer independiente». Hay un reconocimiento implícito hacia lo que socialmente significa ser mujer en México, un discurso que encuentra en el aparato de gobierno y sus instituciones a uno de sus principales promotores; dicha simbolización forma parte de un «dispositivo», esto es, un sistema de significados ya no exclusivamente verbales (Jäger 2001), que sobrevalora la figura de la mujer a partir de considerarla inferior. Por esto, el sintagma «mujer independiente» cobra mayor peso para cerrar el círculo argumentativo. Este aspecto del discurso de Rivera pretende imprimir un valor agregado: al poner énfasis en el carácter de «independiente», se visibiliza que la normalidad percibida por la actriz para vivirse mujer en México es como «dependiente», por lo general de un hombre, esposo, padre, tío, hermano, hijo. Sin embargo, este no es el caso de la actriz, cuya biografía contrasta con este modelo pues ha trabajado desde los 15 años, ha sido actriz y conductora, ha atravesado por un divorcio y ha tenido que ver por sus hijas y por su madre. Ella es una mujer independiente, honrada, con valores, que ha trabajado siempre; por eso, la falsa acusación le molesta, pero sobre todo le indigna.

\subsection{Valores en el episodio «¿Salvar el Matrimonio?» de Destilando amor}

Televisa, el conglomerado de medios de comunicación más importante de México e Hispanoamérica por tamaño de público al que llega y por la diversidad de contenidos que produce, compró en 2006 los derechos para producir una versión de la telenovela colombiana Café con aroma de mujer, que entre 1994 y 1995 tuvo gran éxito en Latinoamérica, Estados Unidos y Europa. 
La producción mexicana, Destilando Amor, reemplazó los cultivos de café por los de agave y fue en su momento una de las telenovelas de mayor audiencia. Según información de la agencia Notimex, reproducida por el diario El Universal ${ }^{16}$ en octubre de 2007, durante el capítulo final de transmisión, 59 de cada 100 televisores de la Zona Metropolitana del Valle de México monitorearon el desenlace de la historia. Destilando amor fue transmitida diariamente, dentro del horario estelar mexicano (20:00 a 23:00 horas) por el canal 2 de Televisa, utilizando la señal pública (abierta) de transmisión. La protagonista fue Angélica Rivera (1969-), papel que ha sido hasta la fecha el más importante en su carrera como actriz. El gran éxito entre el público mexicano (a pesar de algunas críticas recibidas debido a que la historia reproducía estereotipos sexistas), ocasionó que Rivera fuera identificada eventualmente con el apodo del personaje que interpretó: Mariana Franco, «La Gaviota». Este apodo, «La Gaviota», sigue asociado a la actriz en la actualidad, y es frecuentemente usado por usuarios de redes sociales y medios de comunicación para referirse a ella.

Del total de 170 episodios de Destilando amor, aquí se analiza uno con el fin de visibilizar el paralelismo discursivo ${ }^{17}$ con la defensa de Rivera en YouTube en 2014. Se trata del episodio 23, titulado «¿Salvar el matrimonio?», que fue seleccionado por el hecho de referir la palabra «matrimonio» en su título y por su semblanza introductoria: «James le sugiere a Rodrigo que se olvide de Gaviota y trate de salvar su matrimonio", sin contar con alguna referencia previa sobre el mismo. No incluyo aquí una síntesis del episodio, pues en él toman lugar distintas historias secundarias, entrelazadas con los 22 episodios previos y los sucesivos y con la trama principal. En su lugar, contextualizo y abordo escenas específicas en las que la temática alude a los argumentos expuestos en $\$ 4.3$.

\subsubsection{El trabajo}

Distintas referencias hacia el trabajo como uno de los valores más importantes en el video de la actriz también se encuentran en el episodio 23. Mariana Franco es una chica que ha emigrado de un pueblo a la Ciudad de México en búsqueda de mejores oportunidades de vida. Trabaja como recepcionista en el «Corporativo Montalvo», pero aspira al puesto de secretaria. En la escena que sigue, Mariana aparece conversando con su madre en el comedor de su casa, aparentemente de clase trabajadora:

${ }^{16}$ <http://archivo.eluniversal.com.mx/notas/449617.html>.

${ }^{17} \mathrm{El}$ análisis comparativo de otros rasgos lingüísticos como la entonación, el léxico, y los patrones sintácticos, así como el estudio de los componentes paralingüísticos, puede ser objeto de una investigación posterior. 
31 MADRE: ¿Y qué tanto lees mija?

32 MARIANA FrANCO: Es información que saqué de internet sobre diplomados ma.

33 MADRE: ¿Diplomados? ¿Y eso con qué se come?

34 MARIANA FrANCO: No ma, son cursos para especializarse en alguna materia que a uno le interese. ¡Mira! Este me puede servir «Diplomado en gerencia estratégica y competitividad».

35 MADRE: Ay eso se oye muy apantallante, pero no entiendo ni papa.

36 Mariana Franco: Es un método para optimizar las acciones de una empresa y adquirir mayor efectividad ¿isí?

37 MADRE: Mmm me quedé en las mismas.

38 MARIANA FrANCO: A ver para que entiendas este curso me va a ayudar para ser mejor, más eficiente en mi trabajo.

39 MADRE: ¿Cómo así, pero pa' qué tanta estudiadera? Usted no lo necesita para ser una buena recepcionista, digo yo.

40 Mariana Franco: Pues sí, pero voy a ser la secretaria del señor Montalvo y tengo que estar bien preparada para cuando eso suceda.

Aparece el deseo de superación personal, estrechamente ligado al ámbito laboral, y a la empresa corporativa. Se aprecian también la perseverancia y el sacrificio de la mujer abnegada que debe invertir su tiempo libre en buscarse una vida mejor. La telenovela juega con la ilusión de que esa búsqueda, aunque larga y cansada, no es eterna, sino que tiene recompensas para los que perseveran y saben esperar.

El trabajo aquí es el elemento central como medio para «superar»la pobreza, pero también la autosuperación de Mariana; como ella misma lo expresa en la línea (38): «para ser mejor, más eficiente en mi trabajo». Se trata de un vínculo entre calidad humana, superación y trabajo, que se obtiene mediante el estudio, la perseverancia y el autosacrificio.

\subsubsection{La familia}

La familia es un valor constantemente presentado y resignificado en la telenovela. Entre el conjunto de construcciones dicotómicas que se observan, campo/ciudad, pobre/rico, masculino/femenino, entre otras, esta redefinición de la familia se realiza bajo los pares antiguo/moderno, pasado/ presente o conservador/liberal. La telenovela presenta la historia de amor «imposible» entre Rodrigo y Mariana, imposible por diferencias entre ambos: él es rico, ella pobre, él se desenvuelve y forma parte de un entorno urbano y ella está habituada a uno rural. Las dificultades que entraña la consumación de este amor, aderezadas desde los primeros episodios por el hecho de que él se casa con Isadora, configuran las diversas historias cotidianas en Destilando amor. Isadora, a diferencia de Mariana, pertenece 
a la misma clase social de Rodrigo, pero es representada como antagonista mediante asociaciones negativas como el interés económico, la superioridad racial y cultural, la avaricia, la envidia y los celos, entre otros.

La mayoría de los personajes antagónicos, entre ellos Isadora, se oponen a consumar el amor entre Mariana y Rodrigo, o sea, a hacerlo posible a través del reconocimiento social. La mayoría pertenecen a una clase social alta y sus actos se orientan hacia el reforzamiento de la unión entre Isadora y Rodrigo, mientras que reprueban el que este siga enamorado de Mariana. En esa dicotomía liberal/conservador, la noción de familia viene asociada con el amor, la pasión, el romance y la felicidad, y se enfrenta a una idea conservadora de matrimonio basado en intereses económicos y de «mejoramiento» del linaje. Ese matrimonio de corte conservador es constantemente caracterizado en el episodio como infeliz y lleno de frustraciones sexuales.

El valor de la familia, por lo tanto, queda planteado en un esquema más flexible: solo si está basada en el «amor real» puede y debe romper con el modelo tradicional, fundado en las «buenas costumbres» de la clase alta y el catolicismo. La infidelidad y el divorcio aparecen justificados siempre y cuando se trate de una relación basada en sentimientos «puros» o «reales». Este es el caso de Angélica Rivera y Enrique Peña Nieto, quienes formaron una nueva familia integrada por ellos y sus respectivas proles, a pesar de ser ella divorciada, y él, viudo. Tanto en la telenovela como en el video de Rivera, la familia se interpreta en clave de ruptura con el matrimonio tradicional, y de paso, se cuestiona el que este sea algo definitivo y vitalicio. Un ejemplo de este replanteamiento de familia-matrimonio aparece en un diálogo entre Rodrigo y James, su amigo británico que trabaja en la hacienda agavera.

41 JAMES: Ah Rodrigo Rodrigo, ¿Cuándo vas a rendirte?

42 Rodrigo: Ay ay.

43 JAMEs: ¿No te das cuenta que por estar con esta obsesión vas a perder tu esposa?

44 Rodrigo: Sí, ya lo sé.

45 JAMEs: En realidad, ¿ya no sientes nada por ella?

46 Rodrigo: No.

47 JAMES: ¿No la deseas?

48 RodRIGO: No. ¿Cuándo vas a entender que Gaviota es la única mujer que me hace sentir un hombre completo?

49 JAMES: ¿Por qué no intenta ${ }^{18}$ tener relaciones con ella? Es una mujer bella, Rodrigo, salva tu matrimonio.

${ }^{18}$ No es error de transcripción. Este personaje, cuyo actor es hablante nativo de español, deja ver ciertas representaciones gramaticales y fonéticas hacia el hablante de español como segunda lengua, especialmente hacia el hablante nativo de inglés. 


\subsubsection{El honor}

En el episodio 23 se presenta un caso que resulta de peculiar interés por su semejanza con la falsa acusación de Rivera en el 2014. Se trata de una escena en la que Mariana Franco llega a su oficina y se encuentra con que el monitor de su computadora de escritorio ha desaparecido; ella es la principal sospechosa y es acusada de haberlo robado. Sus compañeros de trabajo le han puesto esta trampa porque no les gusta el trato preferencial que recibe del director del «Corporativo Montalvo», así que pretenden conseguir su despido.

[Mariana entrando a la oficina]

50 ELVIRA (secretaria): ¡Ahí viene, ahí viene!

51 MARIANA: ¿Qué pasa aquí?

52 LiCENCIADO: Dígame ¿dónde estaba usted Mariana?

53 Mariana: Me fui a comer, licenciado ¿Por qué?

54 LicEnCIAdo: Porque el monitor de la computadora ha desaparecido.

55 Mariana: Pero aquí estaba antes de que yo me fuera.

56 LiCENCIADO: ¿Usted sabe cuánto cuesta el monitor de una computadora?

57 ELVIRA: ¡Una barbaridad!

58 MARIANA: ¿Por qué me miran así? Licenciado, yo no me llevé el monitor, de verdad.

59 LiCENCIADO: Mariana en esta empresa tenemos reglas muy claras, los empleados responden por el equipo de trabajo que usan.

60 ELVIRA: ¡Y responden con su plaza!

61 MARIANA: A ver ¿y por qué yo soy la única sospechosa?

62 Elvira: Porque desapareció justo cuando tú te fuiste a comer.

63 MARIANA: Es que pudo ser otra persona iyo no fui!

64 Elvira: ¡Oh sí!

65 Plácido (intendente): Nadie más se acercó al mostrador.

66 MARIANA: ¡Me están acusando de ladrona!

67 LiCENCIADO: Tranquilícese, por favor.

68 MARIANA: Es que ¿cómo me voy a tranquilizar? Yo no me robé nada, se lo juro por Dios.

[Entra Aarón Montalvo, director del corporativo]

69 AARÓN: ¡¿Qué está pasando aquîi?!

70 Elvira: Señor Montalvo, desapareció el monitor de la computadora, bueno mejor dicho se lo robaron y la señorita Franco tiene que responder por eso.

71 LiCENCIADO: Aarón, desafortunadamente tendremos que despedirla.

72 AARÓN: ¿Usted cree que Mariana robó el monitor?

73 Licenciado: No lo sé, pero tenemos una reglamentación muy estricta y si no la hacemos cumplir vamos a sentar un mal precedente entre los empleados.

74 AARÓN: Mariana. 
75 MARIANA: Sí señor.

76 AARÓn: La hago responsable del robo del monitor.

77 MARIANA: ¿Cómo?

78 AARÓn: Usted tiene que responder por el robo del monitor.

79 MARIANA: Yo no soy ninguna ratera señor de verdad, alguien aprovechó mi salida a comer para llevárselo.

80 Elvira: Ay Mariana, no seas cobarde, acepta tu falta.

81 MARIANA: ¡Aquí la única cobarde es la persona que se robó la mentada pantalla de la computadora, y estoy segura que no va a aparecer porque lo hicieron para perjudicarme y yo sé quién fue señor.

\section{[Se dirige a Elvira]}

82 ELVIRA: ¿Qué estás insinuando?

83 MARIANA: ¡Yo no estoy insinuando nada! Estoy asegurando quién fue.

84 AARón: Se acabó la discusión ¡despejen el lugar! ¡que se vayan! Señorita Franco acompáñeme a la oficina.

En los enunciados (66) y (68), a Mariana le resulta inconcebible el hecho de estar siendo acusada de algo que ella sería incapaz de hacer; está alterada y, ante la petición «tranquilícese por favor», responde con mayor sorpresa: ante tal acusación no es posible tranquilizarse sino al contrario, escandalizarse. Es decir, se trata de un insulto al honor de magnitudes desproporcionadas. Cuando entra el director del corporativo, también expresa sorpresa al preguntar al licenciado si en verdad piensa que Mariana robó el monitor, a lo que el licenciado responde que él solo cumple con su deber, que es hacer respetar el reglamento. Hacia el final de la escena, sale a la luz la verdadera razón detrás de la acusación, expresada por Mariana: el motivo por el que alguien la acusaría de este agravio es que quieran perjudicarla (81). La escena continúa en la misma línea de indignación, como se observa en (90), y la explicación de que hay personas que la quieren echar de la oficina en (94):

[Mariana entra en la oficina de Aarón Montalvo]

85 AARÓN: Siéntese señorita Franco.

86 MARIANA: Gracias pero es que no me puedo sentar, me da mucha pena, pero es que estoy ique trino de coraje!

87 AARón: Mariana, lamento mucho lo que pasó, pero ya le expliqué, en la empresa tenemos reglas muy precisas.

88 MARIANA: Sí, sí, ya me di cuenta, esas reglas sirven para escarmentar a los empleados cacomizcleros y todo lo que usted quiera, pero también para fines muy mezquinos.

89 LICENCIADO: ¿Qué quieres decir con eso?

90 MARIANA: Que a mí se me ha metido entre ceja y ceja que algunas personas me quieren echar de aquí, y que algunas cuando me ven se les fruncen las tripas y a cualquier precio quieren quitarme del camino. 
91 LiCENCIADO: Mariana nosotros entendemos...

92 Mariana: Discúlpeme licenciado, mire, déjeme terminar se lo suplico, es que solo así me calmo. Señor Montalvo ¿a usted le parece que yo hice antesala por más de un mes, casi me mato por venir a trabajar aquí, solo para robarme un triste monitor de computadora? ¿A ver licenciado, a usted le parece que yo tengo cara de ratera?

93 LicenCIADO: Nooo.

94 MARIANA: ¡No, pues claro que no! Ni estando en la vil chilla yo me robaría un lápiz del corporativo, pero es que también estoy muy decepcionada porque, yo pensé que había logrado dar una imagen profesional, pensé que ustedes se habían dado cuenta que soy una mujer íntegra y con una sola meta, crecer y dar lo mejor de mí.

95 AARón: Mariana, créame que entiendo su molestia, pero nosotros no podemos hacer ninguna excepción a las reglas.

96 Mariana: Perdóneme señor, pero pero es que yo no estoy pidiendo que haga ninguna excepción conmigo ni nada de eso, no, ¿usted tiene que sancionarme? Sí porque me lo merezco, pero la verdad es que no por ratera, sino por confiada y mensa, a ver, ¿cuánto cuesta el dichoso monitor de la computadora? Porque yo no les voy a pagar uno, les pago dos, les pago tres, los que sean, así dure un año endeudada aquí, mejor dicho, de ahora en adelante voy a pagar todo lo que se pierda en esta bendita empresa.

97 Licenciado: Mariana, como bien dices te mereces una sanción por inexperta, así que por favor arregla ese pendiente con el licenciado Quintana.

En el enunciado (92), Mariana apela a la lógica para demostrar su inocencia y emplea su apariencia física para validar su bondad: "¿A ver licenciado, a usted le parece que yo tengo cara de ratera?». El enunciado (94) constituye un buen ejemplo de la "pobre pero honrada», que ni en la peor de las miserias ( «estando en la vil chilla» ${ }^{19}$ ) se robaría «ni un lápiz». A la indignación se le suma la decepción, pues a pesar de su comportamiento recto, intachable, a través del cual ha querido dar una «imagen profesional», se percata de que no lo ha logrado. Aparece finalmente una alusión a la mujer: «una mujer íntegra y con una sola meta, crecer y dar lo mejor de mí». Al igual que en el caso del video de YouTube, observamos que en la telenovela de 2007 los valores se entrecruzan en un modelo de persona: el trabajo, el honor y la mujer.

19 Esta expresión, como muchas otras que han aparecido en las transcripciones correspondientes a la telenovela, son propias del español del centro del país, en particular de la Ciudad de México y su zona metropolitana. Aunque se requeriría una investigación mucho más detallada, puede afirmarse que las telenovelas mexicanas reproducen usos lingüísticos representativos de la capital mexicana y sus alrededores. 


\subsubsection{La mujer}

La escena referida en el apartado anterior corresponde a una de las subhistorias más importantes de todo el episodio, quizás es la más importante por su ubicación y extensión, que comienza alrededor de la mitad del capítulo y se extiende, de manera intermitente, hasta el final. Su desenlace vincula nuevamente el trabajo y el honor, pero especialmente el «honor de mujer»:

\section{[Oficina del licenciado Quintana]}

98 MARIANA: El señor Montalvo me dijo que hablara con usted, por el asunto del monitor de la computadora.

99 Licenciado Quintana: Así es, tiene que firmar este documento, donde autoriza que se le vaya descontando de su sueldo, [se levanta del escritorio y comienza a caminar hacia Mariana] tuvo suerte de que no la despidiera, ojalá no incluya este incidente en el reporte de la junta de consejo.

100 MARIANA: ¿Y por qué tendría que informar de algo tan insignificante? A ver ¿dónde firmo?

101 Licenciado: Déjeme decirle dónde, a ver permítame [acerca su cara al oído de Mariana y ella se aleja]. Aquí. Espero que ese dinero no le haga falta. Me dolería mucho descontárselo, una pregunta, ¿vive sola?

102 Mariana: Con mi mamá.

103 LiCENCIADO: Esta noche habrá una degustación en la asociación, bueno Aarón no puede ir y, bueno pues, yo iré representando a la empresa, ¿quiere acompañarme?

104 MARIANA: ¿Acompañarlo?

105 Licenciado: Sí, serviría para conocernos mejor y tal vez mañana canalice el monto del robo a otra cuenta de la empresa, bueno pues usted recibirá su primer sueldo completo, ¿cómo la ve? Y después de la degustación podemos irnos a otra parte.

106 Mariana: ¿A dónde?

107 LicenCIADO: A otra parte...

[Mariana se levanta de la silla y lo abofetea]

108 MARIANA: ¡No vuelva a intentar eso, porque yo no me voy a vender por nada y si tengo que pasar el resto de mi vida pagando por esa mentada pantalla, no me importa!

Es en el enunciado (108) donde se observa una alusión indirecta al «honor de mujer» entendido como valor, pues Mariana, al mencionar que «no se va a vender por nada», remite a una mujer ejemplar, definida en oposición a una prostituta. 


\section{Discusión}

Tras la identificación de los valores que se erigen como argumentos en la defensa en YouTube de la actriz Angélica Rivera, una primera reflexión por presentar es que los valores de «trabajo», «familia», «honor»y «mujer» se encuentran todos entrecruzadas y configuran lo que Jäger denomina un enmarañamiento discursivo (2001: 85), en el que aparecen evidenciados diversos planos de la realidad social. En línea similar, el concepto de jerarquía en la argumentación, de Perelman y Olbrechts-Tyteca (1969), resulta de utilidad también. En la jerarquización de valores que hace Rivera se aprecia la oscilación entre valores abstractos y concretos, según la categoría de estos autores, al constituir oportunidades de resignificación que la actriz mexicana realiza para persuadir a su audiencia. Este proceso de resignificación se aprecia en el conjunto de valores que aquí se han identificado, pero de manera especial en el caso de la «familia», expuesto en $\$ 4.3 .2$ con mayor detalle.

Idealmente, este enmarañamiento discursivo, o jerarquía de valores reunidos en el material abordado, es susceptible de un análisis mucho más detallado que incorpore, además de la dimensión histórica, otros aspectos en el orden no solo de lo lingüístico, sino también de lo discursivo/argumentativo. En este sentido, queda pendiente, por ejemplo, estudiar el uso de otras estrategias audiovisuales dispuestas para participar en el proceso de persuasión, no ubicadas en el terreno de lo verbal; tal es el caso de la producción audiovisual, los movimientos de cámara (close-ups y planos medios), la utilería, la escenografía, el vestuario, además de los contenidos paralingüísticos: la interacción de Rivera con la cámara, sus expresiones faciales y movimientos corporales.

A pesar de estas ausencias, este trabajo ha pretendido centrar la problemática en uno solo de los aspectos que componen el ejercicio de la argumentación planteado por Perelman y Olbrechts-Tyteca, aquel que los autores denominan como «acuerdo de las premisas», en específico las que ubican en el orden de «lo preferible», y que sirven como principios de acuerdo sobre los que parte la argumentación. Como una continuación a estos planteamientos queda pendiente un análisis que profundice en la elección de estos acuerdos, así como en su presentación. Es importante reconocer que la identificación de los valores aquí desglosada (tanto como la lectura teórica que se ha hecho de ellos), no es la única posible, otros valores también podrían ser extraídos del discurso de Rivera para ser tomados en cuenta en la jerarquía. No obstante, consideramos que este análisis ha permitido visibilizar la presencia del conjunto de valores retomados, y, sobre todo, el hecho de haberse naturalizado en el discurso de la actriz, al grado que son empleados como premisas de acuerdo, o como bases fundamentales con las que pretende conseguir su defensa pública. 
Adicionalmente, asumiendo que la naturalidad con la que la actriz emplea estos valores es síntoma de la convicción de que con ellos podrá conseguir su propósito, este análisis ha pretendido ofrecer una explicación al rechazo al video manifestado por la sociedad y la opinión pública mexicana, al menos aquella opinión pública activa en las redes sociales, al verse y sentirse mal representada, o distorsionada, en el espejo que Rivera le proponía como condición previa al lavado de su imagen. Más allá de una limpieza de imagen, lo que la actriz consiguió fue una construcción errónea y anacrónica de su auditorio, los mexicanos, dejando expuestas la visión y la imaginación que tienen de la sociedad las cúpulas del poder en México.

Hay que subrayar que resulta muy probable que la producción de este video hubiera contado con la asesoría de equipos de comunicación y análisis político, por involucrar el caso a funcionarios y dependencias del gobierno federal, entre ellos su esposo el presidente, de quien estaba en duda la credibilidad de su declaración patrimonial, y, en últimas, la violación a un mandato constitucional. Por este motivo, se asume que no fue ella quien ideó y realizó la respuesta al reportaje de Aristegui Noticias. Observado bajo este supuesto, el video constituiría una estrategia política de comunicación pública que la Presidencia de la República operó en YouTube.

La defensa de Rivera, por otra parte, refleja la materialización de una ideología en términos de Althusser (1995), en tanto emplea valores que aparentemente se encuentran extendidos en la sociedad y recurre a ellos para conseguir la persuasión del auditorio que la oradora proyecta. Son estos valores los que aparecen como prácticas aceptadas y generalizadas en dicha estrategia política. Para Althusser, los aparatos ideológicos de estado reproducen y contribuyen a perpetrar el orden social basado en una concepción dominante-dominado; como parte de estos, los medios de comunicación participan en esa configuración de la realidad social. La industria cultural (Horkheimer y Adorno 1944 [2002]) contribuye de este modo a explicar el origen de estas prácticas diseñadas por quienes ejercen el poder. En 2011, por citar un ejemplo, el 98,8\% de la población mexicana contaba con televisión en sus hogares, según la empresa IBOPE-AGM (citado en Rodríguez 2014). En los hogares mexicanos hubo, al menos, una televisión encendida durante poco más de ocho horas al día, y en promedio los mexicanos consumieron per cápita 4,15 horas de televisión por día en ese año. En cuanto al tipo de material consumido, IBOPE reporta que para el periodo 2009-2010, el 78,5\% se trató de televisión abierta y que «entre los 15 primeros lugares de preferencia, diez fueron ocupados por telenovelas». Una revisión detallada de las telenovelas producidas por Televisa mostraría cómo los temas recurrentes de este género televisivo en México tienen que ver con historias que colocan al «amor real» en el punto más alto de una estructura de valores, en torno a la cual giran otros como el 
trabajo, la pobreza, el papel de la familia, la dignidad, el honor, la mujer abnegada y la mujer independiente.

A partir de la comparación del video de YouTube con el episodio 23 de Destilando Amor, se plantea que el primero exhibe la continuación del personaje de Mariana Franco, «la Gaviota», en una situación distinta a las de la telenovela, una situación en la que Mariana ha resultado victoriosa de todas las adversidades, ha vencido a los antagonistas, ha conseguido romper con el convencionalismo del matrimonio tradicional y está casada por amor. Sin embargo, en este escenario ideal aparece un evento disruptivo, constituido por las acusaciones de corrupción por tráfico de influencias y la difamación contra su familia. Esto altera el orden y provoca la reacción de la «Primera Dama» en tono de indignación, es así que debe salir a defender al esposo y a la familia por los que tanto había luchado. Una reacción como esta es la que corresponde adoptar ante una "falsa acusación», una reacción con la que la audiencia ya estaba familiarizada en momentos como el robo del monitor en el episodio 23. En otras palabras, Rivera reacciona de la misma manera en que lo haría «la Gaviota» si estuviera en sus zapatos.

Es en este paralelismo donde reside la estrategia política detrás del video de YouTube y es ahí donde radica el poder persuasivo que pretendió ejercer. Ante una acusación que se vive como falsa, la indignación de Angélica Rivera es el cansancio de Mariana Franco. Si esta hipótesis es cierta, es decir, si aceptamos la correlación de estos hechos y los tomamos como una verdad, siguiendo a Perelman y Olbrechts-Tyteca, estaríamos en efecto ante una actuación más de la actriz Rivera; aunque, también, ante una pseudorrepresentación de la audiencia, la sociedad mexicana, llevada a cabo por la actriz, la familia presidencial y los involucrados en la producción del video, que explicarían la ola de reacciones negativas que este generó luego de su aparición el 18 de noviembre de 2014 en Aristegui Noticias.

Se identifica, por lo tanto, que:

1) Angélica Rivera no ideó ni produjo por sí misma el video que aparece en su canal personal de YouTube, sino que se trató de una maniobra política planificada.

2) Esta maniobra de comunicación reprodujo una temática, una narrativa y una estructura de valores que es posible rastrear en las telenovelas mexicanas, así como otros elementos lingüísticos y paralingüísticos asociados a estas.

3) Rivera ha sido actriz de estas telenovelas producidas por Televisa, lo que refuerza la idea de que se trata de una estrategia de comunicación de la que se esperaba obtener un impacto positivo en la audiencia.

4) La industria cultural en México ha contribuido a la circulación de estos sistemas de valores a lo largo del siglo $\mathrm{xx}$, los cuales han sido 
percibidos por las esferas de poder como los valores sociales extendidos, como se puede inferir del material estudiado.

5) El matrimonio presidencial y los involucrados en la realización del video habrían apostado así a la idea de que esos valores son, en efecto, los predominantes en la sociedad mexicana contemporánea, apuesta que explicaría la decisión de emplear el estilo de molestia e indignación de Rivera en YouTube; tal percepción se aprecia también en la convicción de crear un video que reproduce las mismas temáticas, estilo discursivo y recursos audiovisuales de una telenovela.

Uno de los propósitos centrales de este trabajo fue demostrar cómo este suceso de la política mexicana se encuentra impregnado de la industria del entretenimiento, y cómo ambas esferas mantienen relaciones complejas que se configuran y quedan expresadas en usos concretos de la lengua. Este planteamiento reconoce y se centra en el carácter político del lenguaje de los políticos, y coincide con Joseph (2006) respecto a que la lengua, desde la de la vida política hasta la que aparece en una telenovela, se encuentra envuelta por lo político.

Otro de los propósitos fue demostrar precisamente cómo, al observar detenidamente esta estrategia de comunicación pública, el gobierno federal mexicano subestima al pueblo que gobierna, al traer elementos de la industria cultural para distraer su atención ante otros asuntos de interés nacional. Es este un acto fallido que, por sí mismo, genera una ola de verdadera indignación en un sector de la sociedad civil. El hecho de que el video de Rivera en YouTube bloqueara a los usuarios la posibilidad de comentar, por un lado, y las más de 1300 expresiones de repudio al gobierno que llegaron a aparecer en Aristegui Noticias y otros medios, en cambio, ponen además en entredicho la eficacia de la telenovela como uno de los dispositivos de control predilectos de la industria cultural y los aparatos ideológicos de estado. El punto de choque radica en que la producción del video parece convencida de dicha eficacia, mientras que la reacción de las audiencias apunta hacia la existencia de un sector social que ha diversificado su consumo mediático.

El malestar contenido en estas reacciones se vincula a su vez con la ofensa que se experimenta al percatarse de que el interlocutor diseña y emite su mensaje a partir de una preconcepción uniforme, anacrónica y ficticia de sí, al mismo tiempo que pretende obtener un beneficio de él, esto es, su opinión favorable. Se vincula también con la confirmación de que la clase gobernante mexicana no ha sido capaz de ver ni reconocerse en los ciudadanos que gobierna, por el simple hecho de que nunca el gobierno ha emanado de otros sectores sociales que no sean aquellos que conforman una élite política, cultural y económica. 


\section{BIBLIOGRAFÍA}

Althusser, Louis (1995): On the reproduction of capitalism: Ideology and Ideological State Apparatuses, London: Verso.

Cabrera, Rafael, Daniel LizÁrraga, Irving Huerta y Sebastián Barragán (2014): «La Casa Blanca de Enrique Peña Nieto». En Aristegui Noticias. $<$ http://ariste guinoticias.com/0911/mexico/la-casa-blanca-de-enrique-pena-nieto/>.

Del Valle, José (2017): «La perspectiva glotopolítica y la normatividad», Anuario de Glotopolítica. Vol. 1, 17-39.

Goffman, Erving (1967 [1982]): Interaction ritual. Essays on face-to-face behavior, New York: Pantheon Books.

HorkHEIMER, Max y Theodor W. Adorno (1944 [2002]): Dialectic of Enlightenment: philosophical fragments, Stanford: Stanford University Press. (Versión Kindle).

JäGER, Sigfried (2001): «Discurso y conocimiento: aspectos teóricos y metodológicos de la crítica del discurso y del análisis de dispositivos». En Ruth Wodak y Michael Meyer (eds.), Métodos de análisis crítico del discurso, Barcelona: Gedisa.

JosepH, John E. (2006): «Overview: How politics permeates language (and vice versa)», Language and Politics, Edimburgo: Edinburgh University Press, 1-21.

Perelman, Chaïm (1982): The realm of rhetoric, Indiana: University of Notre Dame Press.

Perelman, Chaïm y Lucie Olbrechts-Tyteca (1969 [2010]): The New Rhetoric. A treatise on Argumentation (Translated by John Wilkinson and Purcell Weaver). Indiana: University of Notre Dame Press.

PRESEEA (2008): «Marcas y etiquetas mínimas obligatorias». Vers. 1.2. 17-02-2008. Proyecto Para el Estudio Sociolingüistico del Español de España y de América. $<$ http://preseea.linguas.net/Portals/0/Metodologia/Marcas_etiquetas_mini mas_obligatorias_1_2.pdf $>$.

RODRÍGUEz GómEz, Roberto (2014): «Televisión, televisoras y crisis educativa en México». Campus Milenio 542 (2014-01-09). <http://www.ses.unam.mx/publi caciones $/$ articulos.php? proceso=visualiza\&idart $=1911>$. 